DOI: https://doi.org/10.47405/mjssh.v6i12.1191

\begin{tabular}{|c|c|}
\hline 4 & Malaysian Journal of Social Sciences and Humanities (MJSSH) \\
\hline 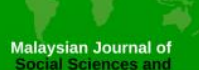 & Volume 6, Issue 12, December 2021 \\
\hline (MJ-sSH) & e-ISSN : 2504-8562 \\
\hline & $\begin{array}{l}\text { Journal home page: } \\
\text { www.msocialsciences.com }\end{array}$ \\
\hline
\end{tabular}

\title{
Do the Dark Triad Personality Traits Buffer against Stress? A Study among Students of Higher Education in Malaysia
}

\author{
Nurhamiza Mumin'1 \\ ${ }^{1}$ Labuan Faculty of International Finance, Universiti Malaysia Sabah (UMS), Malaysia \\ Correspondence: Nurhamiza Mumin (miza@ums.edu.my)
}

\begin{abstract}
Stress and anxiety are prominent mental-health issues among students worldwide. The current students of higher education are digital natives who are accustomed to immediate feedback and instant gratifications. Therefore, they are susceptible to stress differently compared to the previous generations. Given the seriousness of the stress-related issue in higher education, this study was conducted to examine the role of dark triad personality (Machiavellianism, narcissism, and psychopathy) as a buffer against stress. The socially aversive and interpersonally adaptive nature of dark personality traits makes them ideal candidates for further investigation on the influence of personality on stress. The Dark Triad Dirty Dozen and Perceived Stress Scale were used to collect data from 549 respondents. Data were analyzed in two stages using Partial-Least Square-Structural Equation Modelling (PLS-SEM). The study revealed that the only dark triad personality that has a role in the increased level of stress is psychopathy. However, the finding was significant among men but not for women. The current study cannot statistically account for the population of different institutional settings since it only captured samples within higher education institutions in Malaysia. Therefore, future research should be extended to wider populations that cover individuals in certain practices or those with a leadership position in any profession.
\end{abstract}

Keywords: Dark triad personality, higher education institution, stress

\section{Introduction}

Technological advancements change the way individuals processes information and situation daily. The information communication technologies (ICTs) enable access to and a rapid flow of information that influence the perceptual process. ICTs created digital natives with elevated usage of the internet, mobile devices, and social media. They are accustomed to instant feedback and immediate gratification. The current students of higher education were mostly born between the year 1995 to early 2010 are considered a generation Z (Kotera et al., 2021). They rely heavily on ICTs and their personal life shaped generally by social media such as Twitter and Instagram (DiMattio et al., 2020). The instant gratifications offer by the internet search engine and social media expose the higher education students to another form of stress which is foreign to the previous generations.

More than 300 million people of all ages which is equivalent to 4.4 percent of the world's population suffer from mental illness (World Health Organization, 2017). According to the Global Health Estimates report (2017), mental illnesses such as stress and depression are more common among women compared to men. The National Health Morbidity Survey (NHMS) reported an increase of 
DOI: https://doi.org/10.47405/mjssh.v6i12.1191

mental health-related issues from 10.7 percent in 1996 to 29.2 percent in 2015 among Malaysians (Institute of Public Health, 2015). The prevalence of mental illness among adults aged 18 years old and above in Malaysia was 2.3 percent (National Institutes of Health, 2019). However, the suicide mortality rate per 100,000 populations reduced from 5.5 percent in 2016 to 2.7 percent in 2017 (World Health Organization, 2020). An individual with specific dispositional characteristics such as low emotional stability (Noser et al., 2014), lack of agreeableness (Paulhus \& Williams, 2002) is more prone to stress and burnout. Despite extensive researches conducted on personality and stress, little is known about the role of dark personality traits in responses to stress (Noser et al., 2014).

Features of the dark personality traits such as being deceptive, manipulative, and aggressive could buffer an individual against stress (Paulhus \& Williams, 2002). The lack of agreeableness (Noser et al., 2014), conscientiousness (Jakobwitz \& Egan, 2006), and humility (Lee \& Ashton, 2005) in the dark personality traits may influence the individual reaction to stress. Due to how socially aversive and interpersonally adaptive dark personality traits are, they might be the ideal contender for a further investigation on the influence of personality on stress (Birkás et al., 2016). Therefore, this study was conducted to examine the influence of dark personality traits (Machiavellianism, narcissism, and psychopathy) on stress among students of higher education. The most dominant dark personality traits on stress were also further investigated in this study.

\section{Literature Review}

\section{Stress among Students of Higher Education in Malaysia}

The most common mental health issues reported by students of higher education in many countries were stress and anxiety (Brown, 2018; Mey \& Yin, 2015). In less than a decade, the number of students who suffered mental health issues in Malaysia doubled from 10 percent in the year 2011 to 20 percent in the year 2016 (Hezmi, 2018). The stress level among students in Malaysia is higher compared to students in the United Kingdom (Kotera et al., 2021). Stress occurs due to the imbalance between internal or external demands and individual resources (Papageorgiou et al., 2019). The leading factors of stress among students in Malaysia are linked to excessive workloads, financial difficulties, and family-related issues (Ministry of Health, 2016; Yusoff et al., 2010; Votta \& Benau, 2014). Moreover, the current effort of restructuring the Malaysian education system and classifying universities into research, teaching, and comprehensive category create more anxiety and uncertainty (Mey \& Yin, 2015; Kotera et al., 2021). Changes in the higher education system will stipulate different academic obligations which consequently increase the level of stress among students. However, it may vary depending on individual characteristics and personal coping strategies.

\section{The Dark Triad Personality Traits}

The dark triad personality traits comprise three malicious dispositions; Machiavellianism, Narcissism, and Psychopathy (Paulhus \& Williams, 2002). Machiavellianism represents by cynicism, manipulative tendencies, and lack of conventional morality (Jonason et al., 2018). While narcissism is characterized by grandiosity, self-centeredness, and entitlement (Kowalski et al., 2019). Lastly, Psychopathy is typified by callous social attitudes, high impulsivity, and lack of empathy (Jauk et al., 2016).

Machiavellianism and psychopathy are linked to a lack of anxiety and emotional coldness (Christie \& Geis, 1970; Hare, 1985). However, psychopathy is more impulsive by nature while narcissism stands apart on the dimension of superior identity (Furnham et al., 2013). Machiavellianism and narcissism are relatively "lighter" dark traits with lesser undesirable social characteristics and faster life strategies (Bailey, 2019). Therefore, Machiavellians and narcissists can function easily in society compared to Psychopath (Furnham et al., 2013). Psychopathy is an innate personality factor and possibly physiological (Decety et al., 2013). 


\section{Machiavellianism and Stress}

Machiavellianism is a tendency to achieve one's own goal with any possible means irrespective of the traditional morality which aligned with Machiavelli's socially aversive argument that immoral behavior is acceptable if goal-directed (Monaghan et al., 2019). Machiavellian tactics are often associated with deceitful interpersonal style, amorality, self-centeredness, and excessive focus on personal gains (Furnham et al., 2013; Muris et al., 2017). Machiavellians are cynical of humanity and perceive individuals as naïve, untrustworthy, selfish, and manipulative (Monaghan et al., 2019). Their pessimistic and unflattering views on humanity are due to a range of psychopathology symptoms such as lack of empathy, detachment, and low emotional intelligence (Al Ain et al., 2013).

Machiavellians are goal-oriented, less impulsive, and equipped with strategic conducts such as calculated and premeditated behavior which consequently leads to a weaker emotional response (Monaghan et al., 2019). By pre-emptively manipulating the situation, Machiavellians can effectively circumvent any efforts to exploit them. Such a view rationale their action and shield them from shame and guilt (Monaghan et al., 2019). The reactivity among Machiavellians in a stressful situation might be decreased due to their premeditated and cautious behavior (Noser et al., 2014). Besides, Machiavellianism is linked to a combination of anxiety, hostility, depression, self- cautiousness with lack of positive emotions, straightforwardness, and altruism (Kowalski et al., 2019).

\section{Narcissism and Stress}

Narcissism derives from vanity and egotistic admiration of one's attributes in the pursuit of gratification (Muris et al., 2017). It is characterized by a prevalent sense of grandiosity, entitlement, and affirmation from others through attention and admiration (Corry et al., 2008; Furnham et al., 2013). Despite exaggerating talents and personal achievements, Narcissists are constantly concerned about how favorable they were perceived by other people (Thomaes et al., 2009). Nevertheless, the value of people depends heavily on their role in assisting Narcissists to accomplish their egotistical goals (Thomaes et al., 2009).

Narcissists are susceptible to any situations that threaten their grandiose self-view (Zeigler-Hill et al., 2013; Zeigler-Hill et al., 2010). They are highly reactive to stressful events that challenge their sense of control and ability to manage negative experiences effectively (Noser et al., 2014). The inclination to ruminate over failure, criticism, and occasional episode of self-loathing expose narcissistic individuals to negative emotions (Thomaes et al., 2009).

\section{Psychopathy and Stress}

Psychopathy tends to disregard social norms and values, indifference, and dishonesty (Muris et al., 2017) which increases the likelihood of goal-oriented and emotionally driven aggression (Noser et al., 2014). They are highly disagreeable, irresponsible, impulsive, and lack conscientiousness (Furnham et al., 2013; Miller et al., 2010). There are two types of psychopathy: primary psychopathy and secondary psychopathy (Levenson et al., 1995). A primary psychopath is cold-hearted and cruel, while a secondary psychopath is defined by an impulsive-anti social dimension (Levenson et al., 1995; Petrides et al., 2011). Researchers acknowledged the existence of a "successful" psychopath who is usually high in primary psychopathy (incline to lie, devious, callous, and ruthless) and low secondary psychopathy (impulsive, short-tempered, and easily frustrated) (Bailey, 2019).

Psychopathy is the most malevolent dark personality due to thrill-seeking, impulsiveness, and lack of empathy (Furnham et al., 2013; Kowalski et al., 2019; Rauthmann, 2012). They are anti-social individuals who embrace a fast-paced approach in life and disregard interactive as well as normative values (Jonason et al., 2018). A psychopath is often intelligent and charming (Bailey, 2019). However, they are vulnerable to frustration and highly reactive to stressful situations (Blair, 2010; Noser et al., 2014). Individuals with a high level of psychopathy are inclined to make riskier decisions under stressful circumstances compared to Machiavellian and Narcissist (Carre \& Jones, 2016). 


\section{Methodology}

\section{Sample}

Snowball sampling was employed to collect data from 549 respondents with age ranges from 21 to 25 years old. Out of 549 respondents, 140 respondents ( 25.5 percent) are male and 409 (74.5 percent) of them are female. Most of the respondents are Chinese (39.5 percent), followed by Malay (27 percent), Indigenous ethnic of Borneo (21.3 percent), and Indians (12.2 percent). Data were collected using an online survey starting January 2020 to May 2021. The survey consists of three sections that collect data related to personal backgrounds, the dark triad personality traits, and perceived stress level among respondents involved.

\section{Measures}

Dark Triad Dirty Dozen (DTDD) was employed to assess the dark personality traits. The 12-item measure assesses three personality traits; Narcissism, Machiavellianism, and Psychopathy. A 5-scale response was used by respondents to indicate their level of agreement on the items involved. Table 1 describes the detailed items employed to measure the dark triad personality traits.

Table 1: The Dark Triad Dirty Dozen subscale and items

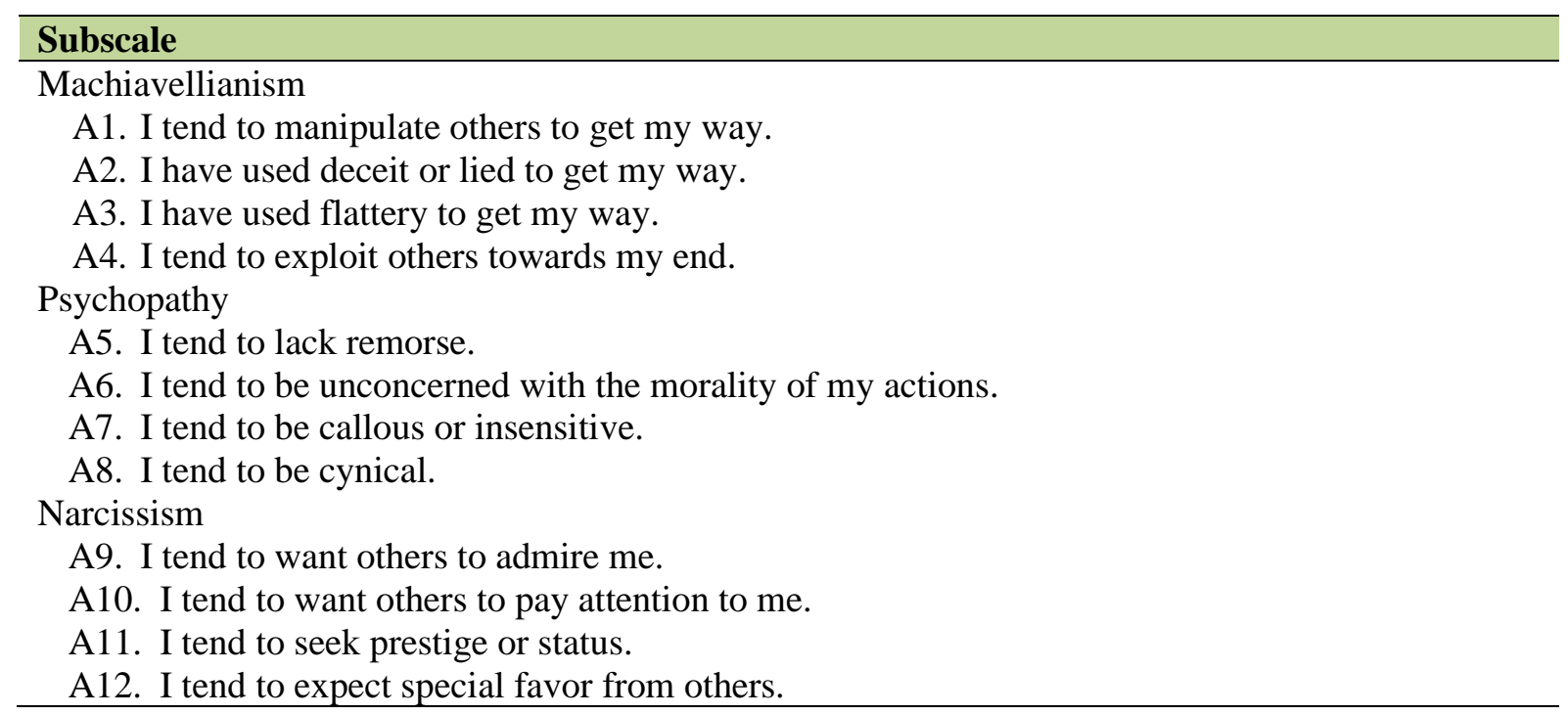

Stress was measured with the Perceived Stress Scale (PSS). The 14-item scale consists of seven negative statements. In each statement, respondents were asked to indicate how often they felt or thought a certain way with a response scale of 1 (never), 2 (rarely), 3 (sometimes), 4 (fairly often), and 5 (very often). A statement such as "In the last month, how often have you felt that things were going your way?" was used to assess stress among respondents involved.

\section{Data Analysis}

Descriptive analysis was used to describe the distribution of age, gender, and ethnicity of respondents involved. The posited relationship between the dark triad personality and stress was assessed using Partial-Least Square-Structural Equation Modelling (PLS-SEM). Data analysis was conducted in two stages; assessment of the measurement constructs, and assessment of the structural model. Measurement constructs and the structural model in this study were formatively developed. Each measurement construct was assessed for validity and any possible multi-collinearity issues. The weightage values were also analyzed for significance and relevance. The structural model was assessed for multi-collinearity issues, followed by the evaluation of path coefficients, and determination of the effect size. 


\section{Result}

\section{Measurement Model Analysis}

The value of the variance inflation factor (VIF) for each indicator ranges from 1.077 to 2.173 fulfilled the required cut-off threshold of 5 (Hair, Hult, Ringle, and Sarstedt, 2014). Therefore, there is no multicollinearity issue among items employed in this study. Despite the non-significant outer weight for 6 indicators (A7, A8, A9, A10, A11, and A12), their outer loadings are higher than 0.5. Thus, all the indicators were retained.

\section{Level of Machiavellianism, Narcissism, Psychopathy, and Stress}

Table 2 indicates the means, standard errors, and standard deviations for Machiavellianism, Narcissism, Psychopathy, and perceived stress. The level of Machiavellianism, Narcissism, and Psychopathy are low with mean values ranging from 2.2035 to 3.0536. The mean value of all dark triad personality traits for male (Machiavellianism $=2.7696$, Psychopathy $=2.5875$, and Narcissism $=$ 3.0536) are higher compared to female (Machiavellianism $=2.2910$, Psychopathy $=2.2037$, and Narcissism $=2.7042)$. However, the perceived level of stress among females is slightly higher $(\mathrm{M}=$ 3.2059) compared to males ( $\mathrm{M}=3.0893)$.

Table 2: Means, standard deviations, and standard errors for the dark triad personality traits and stress

\begin{tabular}{llccc}
\hline & Mean & Std. Error & Std. Deviation \\
\hline Male & Machiavellianism & 2.7696 & .06477 & .76635 \\
& Psychopathy & 2.5875 & .06560 & .77618 \\
& Narcissism & 3.0536 & .07283 & .86175 \\
& Perceived Stress & 3.0893 & .03481 & .41182 \\
\hline Female & Machiavellianism & 2.2910 & .03777 & .76377 \\
& Psychopathy & 2.2035 & .03308 & .66902 \\
& Narcissism & 2.7042 & .04453 & .90047 \\
& Perceived Stress & 3.2059 & .02038 & .41221 \\
\hline
\end{tabular}

\section{The relationship between the Dark Triad Personality and Stress}

Table 3 presents path coefficients, t-values, p-values, and significance levels of the dark triad personality traits and stress. There is no significant relationship between the dark triad personality traits and stress except for psychopathy and stress among males $(r=0.370)$. Despite the different outcomes of the relationship between psychopathy and stress among respondents of different gender, the overlapping confidence intervals are shown in Table 4 indicate there is no difference in path coefficients between the Male and Female samples.

Table 3: Correlations between the dark triad personality traits and stress

\begin{tabular}{ccccc}
\hline & $\begin{array}{c}\text { Path } \\
\text { coefficient }\end{array}$ & t-value & p-values & $\begin{array}{c}\text { Significance } \\
\text { level }\end{array}$ \\
\hline $\begin{array}{c}\text { Machiavellianism -> Stress } \\
\text { Female }\end{array}$ & 0.064 & 0.846 & 0.398 & NS \\
Male & 0.144 & 0.800 & 0.424 & NS \\
\hline $\begin{array}{c}\text { Narcissism -> Stress } \\
\text { Female }\end{array}$ & 0.318 & 1.546 & 0.122 & NS \\
Male & 0.206 & 0.579 & 0.563 & NS \\
\hline $\begin{array}{c}\text { Psychopathy -> Stress } \\
\text { Female }\end{array}$ & 0.171 & 1.082 & 0.279 & NS \\
Male & 0.370 & 2.016 & 0.044 & $* * *$ \\
\hline
\end{tabular}


DOI: https://doi.org/10.47405/mjssh.v6i12.1191

Table 4: Confidence Intervals (Bias Corrected)

\begin{tabular}{lcc}
\hline & Lower bound & Upper bound \\
\hline Machiavellianism $\rightarrow$ Stress & & \\
Female & -0.122 & 0.178 \\
Male & -0.368 & 0.395 \\
\hline Narcissism $\rightarrow$ Stress & & \\
Female & -0.372 & 0.441 \\
Male & -0.572 & 0.597 \\
\hline Psychopathy $\rightarrow$ Stress & & \\
Female & -0.274 & 0.311 \\
Male & -0.067 & 0.601 \\
\hline
\end{tabular}

\section{Discussion}

This study found that the stress level is higher among females compared to their counterparts which is in line with Gallagher et al. (2014). Female tends to express their feeling as a coping mechanism to stressful events (Forushani \& Besharat, 2011). They tend to over-report medical and psychological symptoms due to high self-expectations and self-consciousness which consequently influence their stated stress level (Vrana \& Lauterbach, 1994; Shamsuddin et al., 2013). Higher stress levels among females can also be attributed to biopsychosocial factors such as social roles and physiological status (Bangasser et al., 2007).

The stress level in this study is higher among females compared to their counterparts which is in line with Gallagher et al. (2014). Female tends to express their feeling as a coping mechanism to stressful events (Forushani \& Besharat, 2011). They tend to over-report medical and psychological symptoms due to high self-expectations and self-consciousness which consequently influence their stated stress level (Vrana \& Lauterbach, 1994; Shamsuddin et al., 2013). Higher stress levels among females can also be attributed to biopsychosocial factors such as social roles and physiological status (Bangasser et al., 2007).

The level of Machiavellianism in this study is low with males scoring slightly higher compared to females. Machiavellians incline to utilize any means regardless of morality in achieving personal goals (Monaghan et al., 2019). The findings can be attributed to feminine cultural values among Malaysians. According to Minkov (2018), the feminine cultural dimension emphasizes compassion rather than competitiveness and desire for fame. Therefore, those who are considerate and believe in compassion are not inclined to capitalize on others despite the circumstances. Moreover, the feminine cultural value may reduce the level of stress due to a lack of competitiveness for achievement and fame. Machiavellians tend to be rational, premeditated, and calculated (Monaghan et al., 2019). Their social ability to take on the attitudes of those around them while subtly manipulating the situation allows the establishment of a powerful social network and extracting desired outcomes (O'Boyle Jr. et al., 2012). The attributes will consequently reduce the possibility of a stressful occurrence. Nevertheless, the findings of this study indicate no significant relationship between Machiavellianism and stress among students.

Narcissism has a dualistic feature, adaptive and maladaptive (Rogoza et al, 2019). Narcissists are characterized by a sense of entitlement, impulsivity, and emotional liability (Thomaes et al., 2009). Nevertheless, they are also warm, charming, friendly, and capable of creating meaningful interpersonal relationships (Muris et al., 2017). Narcissists consider themselves as good leaders (Furtner et al., 2011) and emotionally intelligent (Petrides et al., 2011), despite being perceived as socially aversive by others (Furtner et al., 2011). Narcissism emphasizes the importance of achievement and admiration through self-promotion and rivalry (Rogoza et al., 2019) which consequently leads to stress. Narcissists are prone to emotional reactions when exposed to stressful situations due to their impulsivity and emotional volatility (Brown, 2018). However, Grover and Furnham (2020) argue that narcissists experience less stress because of their lack of concern over others and fixation with self-interest. In 
agreement with Noser and Besser (2014), there is no significant relationship between narcissism and stress was found in this study.

Previous researches found that psychopath has less flexible behavior (Jones, 2014), are uncontrolled, impulsive, lack discipline, and have an erratic lifestyle (Muris et al., 2017). Due to the characteristics of psychopathy, they are inclined to be more reactive to stress (Noser et al., 2014). This study found a positive association between psychopathy and stress among males. However, there is no significant relationship between psychopathy and stress among females in this study. It can be explained by the fact that individual with a high level of psychopath often has lack impulse control (Jones \& Paulhus, 2017) and a low tolerance for frustration (Bettencourt et al., 2006). Individuals with low tolerance of stress and a high level of psychopathy are inclined to adopt a confrontative coping strategy in a stressful event (Birkás et al., 2016). When triggered with unplanned stressful situations which often lead to frustration, individual with a high level of psychopathy tends to have a more aggressive reaction (Berkowitz, 1993; Noser et al., 2014).

\section{Conclusion}

Given the seriousness of the stress-related issue in higher education, this study set out to examine the role of dark triad personality as a buffer against stress. The only dark triad personality that has a role in the increased level of stress among students is psychopathy. However, the finding is significant among males but not for females. Therefore, further study should consider situations in which the dark triad personality interacts with other variables such as different demographic factors and institutional settings. It seems likely that different sociodemographic factors would create some basis for rationalization of stress among individuals with diverse dark personality traits. The current study cannot statistically account for the population of different institutional settings since it only captures samples within higher education institutions in Malaysia. A future study should be extended to wider populations that cover individuals in certain practices or those with a leadership position in any profession.

\section{References}

Al Ain, S., Carre, A., Fantini-Haiwel, C., Baudouin, Jean-Yves, \& Besche-Richard, C. (2013). What is the emotional core of the multidimensional Machiavellian personality trait? Frontiers in Psychology, 4(454), 1-8. https://doi.org/10.3389/fpsyg.2013.00454

Bailey, C. D. (2019). The joint effects of narcissism and psychopathy on accounting students' attitudes towards unethical professional practices. Journal of Accounting Education, 49, 1-24. https://doi.org/10.1016/j.jaccedu.2019.08.001

Bangasser, D. A., Curtis, A., Reyes, B. A., Bethea, T. T., Parastatidis, I., Ischiropoulos, H., Van Bockstale, E. J., \& Valentino, R. J. (2010). Sex differences in corticotropin-releasing factor receptor signaling and trafficking: Potential role in female vulnerability to stress-related psychopathology. Molecular Psychiatry, 15, 896-904.

Baughman, H. M., Dearing, S., Giammarco, E., \& Vernon, P. A. (2012). Relationships between bullying behaviors and the Dark Triad: A study with adults. Personality and Individual Differences, 52, 571-575.

Berkowitz, L. (1993). Aggression: Its causes, consequences, and control. Mcgraw-Hill.

Bettencourt, B. A., Talley, A., Benjamin, A. J., \& Valentine, J. (2006). Personality and aggressive behavior under provoking and neutral conditions: A meta-analytic review. Psychological Bulletin, 132(5), 751-777. doi:https://doi.org/10.1037/0033-2909.132.5.751

Birkás, B., Gács, B., \& Csathó, A. (2016). Keep calm and don't worry: Different Dark Triad traits predict distinct coping preferences. Personality and Individual Differences, 88, 134-138.

Blair, R. J. (2010). Psychopathy, frustration, and reactive aggression: The role of ventromedial prefrontal cortex. British Journal of Psychology, 101(3), 383-399. doi:https://doi.org/10.1348/000712609X418480 
Brown, J. S. (2018). Student mental health: Some answers and more questions. Journal of Mental Health, 27(3), 193-196. doi: 10.1080/09638237.2018.1470319

Brown, R. P., Budzek, K., \& Tamborski, M. (2009). On the meaning and measure of narcissism. Personality and Social Psychology Bulletin, 35, 951-964.

Carre, J. R., \& Jones, D. N. (2016). The impact of social support and coercion salience on Dark Triad decision making. Personality and Individual Differences, 94, 92-95. https://doi.org/10.1016/j.paid.2016.01.00

Christie, R., \& Geis, F. L. (1970). Implications and speculations. In R. Christie \& F. L. Geis, Studies in Machiavellianism (pp. 350-358). New York: Academic Press.

Corry, N., Merritt, R. D., Mrug, S., \& Pamp, B. (2008). The factor structure of the Narcissistic Personality Inventory. Journal of Personality Assessment, 90, 593-600.

Decety, J., Chen, C., Harenski, C., \& Kiehl, K. A. (2013). An fMRI study of affective perspective taking in individuals with psychopathy: Imagining another in pain does not evoke empathy. Frontiers in Human Neuroscience, 7(489), 1-12. https://doi.org/10.3389/fnhum.2013.00489

DiMattio, M. J. K., \& Hudacek, S. S. (2020). Educating Generation Z: Psychosocial dimensions of the clinical learning environment that predict student satisfaction. Nurse Education in Practice, 49, 102901. https://doi.org/10.1016/j.nepr.2020.102901

Forushani, N. Z., \& Besharat, M. A. (2011). Relation between emotional intelligence and perceived stress among female students. Procedia - Social and Behavioral Sciences. 30, pp. 1109-1112. Elsevier. doi:10.1016/j.sbspro.2011.10.216

Furnham, A., Richards, S. C., \& Paulhaus, D. L. (2013). The Dark Triad of personality: A 10 year review. Social and Personality Compass, 3(7), 199-216. doi:10.1111/spc3.12018

Furtner, M. R., Rauthmann, J. F., \& Sachse, P. (2011). The self-loving self-leader: An examination of the relationship between self-leadership and the Dark Triad. Social Behavior and Personality, 39, 369-380.

Gallagher, C. T., Mehta, A. N. V., Selvan, R., Mirza, I. B., Radia, P., Bharadia, N. S., \& Hitch, G. (2014). Perceived stress levels among undergraduate pharmacy students in the UK. Currents in Pharmacy Teaching and Learning, 6, 437-441. doi:http://dx.doi.org/10.1016/j.cptl.2014.02.004

Grover, S., \& Frunham, A. (2020). Does emotional intelligence and resilience moderate the relationship between the Dark Triad and personal and work burnout? Personality and Individual Differences. doi:https://doi.org/10.1016/j.paid.2020.109979

Hair, J. F., Hult, G. T. M., Ringle, C. M., \& Sarstedt, M. (2014). A primer on Partial Least Squares Structural Equation Model (PLS-SEM). USA: SAGE Publications, Inc.

Hare, R. D. (1985). Comparison of procedures for the assessment of psychopathy. Journal of Consulting and Clinical Psychology, 53, 7-16. https://doi.org/10.1037/0022-006X.531.7

Institute of Public Health. (2015). National Health \& Morbidity Survey 2015: Non-communicable diseases, risk factors \& other health problems. Institute for Public Health, National Institutes of Health http://www.iku.gov.my/images/IKU/Document/REPORT/nhmsreport2015vol2.pdf

(NIH).

Jakobwitz, S., \& Egan, V. (2006). The Dark Triad and normal personality. Personality and Individual Differences, 40(2), 331-339. https://doi.org/10.1016/j.paid.2005.07.006

Jauk, E., Freudenthaler, H. H., \& Neubauer, A. C. (2016). The Dark Triad and trait versus ability emotional intelligence: Emotional darkness differs between women and men. Journal of Individual Differences, 37(2), 112 - 118. doi:10.1027/1614-0001/a000195

Jonason, P. K., Foster, J. D., Kavanagh, P. S, Gouveia, V. V., \& Birkas, B. (2018). Basic values and the Dark Triad Traits. Journal of Individual Differences, 39(4), 220 - 228. https://doi.org/10.1027/1614-0001/a000267

Jones, D. N. (2014). Risk in the face of retribution: Psychopathic individuals persist in financial misbehavior among the dark triad. Personality and Individual Differences, 67, 109 - 113. https://doi.org/10.1016/j.paid.2014.01.030.

Jones, D. N., \& Paulhus, D. L. (2017). Duplicity among the dark triad: Three faces of deceit. Journal of Personality and Social Psychology, 113, 29-342. https://doi.org/10.1037/pspp0000139.

Jones, D. N., \& Paulhus, D. L. (2011). Differentiating the Dark Triad within the interpersonal circumplex. In L. M. Horowitz \& S. Strack, Handbook of interpersonal psychology: Theory, research, assessment, and therapeutic interventions. (pp. 249 - 268). New York: Wiley. 
Kotera, Y., Ting, Su-Hie, \& Neary, S. (2021). Mental health of Malaysian university students: UK comparison, and relationship between negative mental health attitudes, self-compassion, and resilience. Higher Education, 81, 403-419. doi:https://doi.org/10.1007/s10734-020-00547-w

Kowalski, C. M., Vernon, P. A., \& Schermer, J. A. (2019). The Dark Triad and facets of personality. Current Psychology. https://doi.org/10.1007/s12144-019-00518-0

Lee, K., \& Ashton, M. C. (2005). Psychopathy, Machiavellianism, and Narcissism in the Five-Factor Model and the HEXACO model of personality structure. Personality and Individual Differences, 38(7), 1571-1582. https://doi.org/10.1016/j.paid.2004.09.016

Levenson, M. R., Kiehl, K. A., \& Fitzpatrick, C. M. (1995). Assessing psychopathic attributes in a noninstitutionalized population. Journal of Personality and Social Psychology , 68(1), 151-158. doi:https://doi.org/10.1037/0022-3514.68.1.151

Lilienfeld, S. O., \& Andrews, B. P. (1996). Development and preliminary validation of a self-report measure of psychopathic personality traits in noncriminal populations. Journal of Personality Assessment., 66, 488-524.

Martin, R. A., Lastuk, J. M., Jeffrey, J., Vernon, P. A., \& Veselka, L. (2012). Relationships between the Dark Triad and humor styles: A replication and extension. Personality and Individual Differences, 52, 178-182.

Mey, C., \& Yin, C. J. (2015). Mental health and wellbeing of the undergraduate students in a research university: a Malaysian experience. Social Indicators Research, 122(2), 539-551. https://doi.org/10.1007/s11205-0140704-9

Miller, J. D., Dir, A., Gentile, B., Wilson, L., Pryor, L. R., \& Campbell, W. K. (2010). Searching for a vulnerable Dark Triad: Comparing factor 2 psychopathy, vulnerable narcissism, and borderline personality disorder. Journal of Personality, 78, 1529-1564.

Ministry of Education Malaysia. (2012). Malaysia Education Blueprint (2013-2025). Putrajaya: Ministry of Education Malaysia. https://www.moe.gov.my/en/muat-turun/penerbitan-danjurnal/pppm-2013-2025-pendidikan-prasekolah-hingga-lepas-menengah/1207-malaysiaeducation-blueprint-2013-2025/file

Ministry of Health Malaysia. (2017). Malaysian mental healthcare performance: Technical report 2016. Ministry of Health Malaysia, Malaysian Healthcare Performance Unit. Putrajaya: Ministry of Health Malaysia. https://www2.moh.gov.my/moh/resources/Penerbitan/Laporan/Umum/Mental\%20Healthcare\% 20Performance\%20Report\%202016.pdf

Minkov, M. (2018). A revision of Hofstede's model of national culture: old evidence and new data from 56 countries. Cross Cultural \& Strategic Management, 25(2), 231-256. doi:10.1108/CCSM-03-2017-0033

Monaghan, C., Bizumic, B., Williams, T., \& Sellbom, M. (2019). Two-dimensional Machiavellianism: Conceptualization, theory, and measurement of the views and tactics dimensions. Psychological Assessment, 1-17. http://dx.doi.org/10.1037/pas0000784

Muris, P., Merckelbach, H., Otgaar, H., \& Meijer, E. (2017). The malevolent side of human nature: A meta-analysis and critical review of the literature on the Dark Triad (Narcissism, Machiavellianism, and Psychopathy). Perspectives on Psychological Science, 12(2), 183-204. doi: $10.1177 / 1745691616666070$

National Institutes of Health. (2019). Non-Communicable Diseases: Risk Factors and other Health Problems. Institute for Public Health, Ministry of Health Malaysia. http://www.iku.gov.my/images/IKU/Document/REPORT/NHMS2019/Report_NHMS2019NCD_v2.pdf

Noser, A. E., Zeigler-Hill, V., \& Besser, A. (2014). Stress and affective experiences: The importance of dark personality features. Journal of Research in Personality, 53, 158-164. http://dx.doi.org/10.1016/j.jrp.2014.10.007

O'Boyle Jr., E. H., Forsyth, D. R., Banks, G. C., \& McDaniel, M. A. (2012). A meta-analysis of the Dark Triad and work behavior: A social exchange perspective. Journal of Applied Psychology, 97(3), 557-579. doi: 10.1037/a0025679

Papageorgiou, K. A., Gianniou, Foteini-Maria, Wilson, P., Moneta, G. B., Bilello, D., \& Clough, P. J. (2019). The bright side of dark: Exploring the positive effects of narcissism on perceived stress through mental toughness. Personality and Individual Differences, 139, 116-124. https://doi.org/10.1016/j.paid.2018.11.004 
Papageorgioua, K. A., Malanchini, M., Denovan, A., Clough, P. J., Shakeshaft, N., Schofield, K., \& Kovas, Y. (2018). Longitudinal associations between narcissism, mental toughness and school achievement. Personality and Individual Differences, 131, 105-110. https://doi.org/10.1016/j.paid.2018.04.024

Paulhus, D. L., \& Williams, K. M. (2002). The Dark Triad of personality: Narcissism, Machiavellianism, and Psychopathy. Journal of Research in Personality, 36, 556 - 563.

Persson, B. (2019). Searching for Machiavelli but finding Psychopathy and Narcissism. Personality Disorders: Theory, Research, and Treatment, 10(3), 235-245. http://dx.doi.org/10.1037/per0000323

Petrides, K. V., Vernon, P. A., Schermer, J. A., \& Veselka, L. (2011). Trait Emotional Intelligence and the Dark Triad Traits of personality. Twin Res Hum Genet, 14(1), 35-41. https://www.cambridge.org/core/terms. https://doi.org/10.1375/twin.14.1.35

Raskin, R. N., \& Hall, C. S. (1979). A Narcissistic Personality Inventory. Psychological Reports, 45(2). https://doi.org/10.2466/pr0.1979.45.2.590

Rauthmann, J. F. (2012). The Dark Triad and interpersonal perception: Similarities and differences in the social consequences of Narcissism, Machiavellianism, and Psychopathy. Social Psychological and Personality Science, 3, 487-496.

Rogoza, R., Kowalski, C. M., \& Schermer, J. A. (2019). Dark Triad traits within the framework of the Circumplex of Personality Metatraits Model. Journal of Individual Differences, 40(3), 168-176. doi:https://doi.org/10.1027/1614-0001/a000289

Shamsuddin, S., Fadzil, F., Wan Ismail, W. S., Shah, S. A., Omar, K., Muhammad, N. A., Jaffar, A., Ismail, A., \& Mahadevan, R. (2013). Correlates of depression, anxiety, and stress among Malaysian university students. Asian Journal of Psychiatry, 6, 318-323. http://dx.doi.org/10.1016/j.ajp.2013.01.014

Thomaes, S., Bushman, B. J., De Castro, B. O., \& Stegge, H. (2009). What makes narcissists bloom? A framework for research on the aetiology and development of narcissism. Development and Psychopathology, 21, 1233-1247. doi:10.1017/S0954579409990137

Veselka, L., Schermer, J. A., \& Vernon, P. A. (2011). Beyond the big five: The dark triad and the supernumerary personality inventory. Twin Res Hum Genet, 14, 158-168. doi: 10.1375/twin.14.2.158

Votta, R. J., \& Benau, E. M. (2014). Sources of stress for pharmacy students in a nationwide sample. Currents in Pharmacy Teaching and Learning, 6(5), 675-681. https://doi.org/10.1016/j.cptl.2014.05.002.

Vrana, S., \& Lauterbach, D. (1994). Prevalence of traumatic events and post-traumatic psychological symptoms in a non-clinical sample of college students. Journal of Traumatic Stress, 7, 289-302.

World Health Organization. (2020). World Health Statistics 2020: Monitoring Health for the Sustainable Development Goals. Geneva: World Health Organization. https://www.who.int/publications/i/item/9789240005105

World Health Organization. (2017). Depression and Other Common Mental Disorders: Global Health Estimates. Geneva: World Health Organization. https://www.who.int/publications/i/item/depression-global-health-estimates

Yusoff, M. S. B., Rahim, A. F. A., \& Yaacob, M. J. (2010). Prevalence and sources of stress among Universiti Sains Malaysia medical students. Malaysian Journal of Medical Science, 17(1), 3037.

Zeigler-Hill, V., \& Besser, A. (2013). A glimpse behind the mask: Facets of Narcissism and feelings of self-worth. Journal of Personality Assessment, 95(3), 249-260. https://doi.org/10.1080/00223891.2012.717150

Zeigler-Hill, V., Myers, E. M., \& Clark, C. B. (2010). Narcissism and self-esteem reactivity: The role of negative achievement events. Journal of Research in Personality, 44(2), 285-292. doi:https://doi.org/10.1016/j.jrp.2010.02.005

Zuroff, D. C., Fournier, M. A., Patall, E. A., and Leybman, M. J. (2010). Steps toward an evolutionary personality psychology: Individual differences in the social rank domain. Canadian Psychology, 51, 58-66. https://doi.org/10.1037/a0018472 